\title{
Human Subthalamic Nucleus in Movement Error Detection and Its Evaluation during Visuomotor Adaptation
}

\author{
Huiling Tan, ${ }^{1}$ Baltazar Zavala, ${ }^{1}$ Alek Pogosyan, ${ }^{1}$ Keyoumars Ashkan, ${ }^{2}$ Ludvic Zrinzo, ${ }^{3}$ Thomas Foltynie, ${ }^{3}$ \\ Patricia Limousin, ${ }^{3}$ and Peter Brown ${ }^{1}$ \\ ${ }^{1}$ Experimental Neurology Group, Nuffield Department of Clinical Neurosciences, University of Oxford, John Radcliffe Hospital, Oxford, OX3 9DU, United \\ Kingdom, ${ }^{2}$ Department of Neurosurgery, King's College Hospital, Kings College, London, SE5 9RS, United Kingdom, and ${ }^{3}$ Sobell Department of Motor \\ Neuroscience and Movement Disorders, University College London Institute of Neurology, London, WC1 3BG, United Kingdom
}

\begin{abstract}
Monitoring and evaluating movement errors to guide subsequent movements is a critical feature of normal motor control. Previously, we showed that the postmovement increase in electroencephalographic (EEG) beta power over the sensorimotor cortex reflects neural processes that evaluate motor errors consistent with Bayesian inference (Tan et al., 2014). Whether such neural processes are limited to this cortical region or involve the basal ganglia is unclear. Here, we recorded EEG over the cortex and local field potential (LFP) activity in the subthalamic nucleus (STN) from electrodes implanted in patients with Parkinson's disease, while they moved a joystick-controlled cursor to visual targets displayed on a computer screen. After movement offsets, we found increased beta activity in both local STN LFP and sensorimotor cortical EEG and in the coupling between the two, which was affected by both error magnitude and its contextual saliency. The postmovement increase in the coupling between STN and cortex was dominated by information flow from sensorimotor cortex to STN. However, an information drive appeared from STN to sensorimotor cortex in the first phase of the adaptation, when a constant rotation was applied between joystick inputs and cursor outputs. The strength of the STN to cortex drive correlated with the degree of adaption achieved across subjects. These results suggest that oscillatory activity in the beta band may dynamically couple the sensorimotor cortex and basal ganglia after movements. In particular, beta activity driven from the STN to cortex indicates task-relevant movement errors, information that may be important in modifying subsequent motor responses.
\end{abstract}

Key words: adaptation; effective connectivity; information flow; movement error; sensorimotor cortex; subthalamic nucleus

\section{Introduction}

The capacity for motor learning allows humans to adapt to perturbations and changes in the environment during movement production. The process of adaptation involves the updating of an internal model driven by the prediction error, i.e., difference between the predicted and actual consequence of a voluntary movement (Wolpert and Miall, 1996), in a manner consistent with Bayesian inference (Korenberg and Ghahramani, 2002; Körding and Wolpert, 2004). Motor adaptation in response to sensorimotor perturbations has been primarily considered a function of the cerebellum (Tseng et al., 2007; Miall and King, 2008). Converging evidence suggests that suppressions in beta

Received Aug. 14, 2014; revised Sept. 28, 2014; accepted 0ct. 20, 2014.

Author contributions: H.T. and P.B. designed research; H.T. and B.Z. performed research;H.T., B.Z., A.P., K.A., L.Z.,

T.F., and P.L. contributed unpublished reagents/analytic tools; H.T. and P.B. analyzed data; H.T., B.Z., A.P., and P.B. wrote the paper.

This work was funded by the Medical Research Council. The work was performed in the National Institute for Health Research Cognitive Health Clinical Research Facility, Oxford.

The authors declare no competing financial interests.

This article is freely available online through the J Neurosci Author Open Choice option.

Correspondence should be addressed to Huiling Tan, Nuffield Department of Clinical Neurosciences, University of Oxford, Level 6, West Wing, John Radcliffe Hospital, Oxford, OX3 9DU, UK. E-mail: Huiling.tan@ndcn.ox.ac.uk.

DOI:10.1523/JNEUROSCI.3414-14.2014

Copyright $\odot 2014$ Tan et al.

This is an Open Access article distributed under the terms of the Creative Commons Attribution License (http://creativecommons.org/licenses/by/3.0), which permits unrestricted use, distribution and reproduction in any medium provided that the original work is properly attributed. oscillations (13-30 Hz) over the sensorimotor cortex are associated with the processing of error feedback (Luft et al., 2014) and cortical reorganization during motor learning (Nakano et al., 2013; Pollok et al., 2014). We reported previously a negative correlation between movement error size and the amplitude of postmovement beta event-related synchronization (ERS) over the sensorimotor cortex in healthy subjects, with this negative correlation enhanced when the contextual salience of movement errors was additionally considered (Tan et al., 2014). Thus, we proposed that the postmovement beta ERS over the sensorimotor cortex reflects neural processes that evaluate the result of a completed movement with respect to its predicted outcome and do so in the context of the previous error history. However, it remains unclear whether the sensorimotor cortex subserves such a function alone or does so with key subcortical interactions.

Here we explore the hypothesis that dynamic input from the basal ganglia makes an important contribution to the system evaluating and adjusting to motor errors, particularly by modulating the cortical beta ERS. The reasons for thinking this are several. First, oscillatory activity in the beta band is widespread in the cortico-basal ganglia network, and beta-band coherence between subthalamic nucleus (STN) and cortical activity increases after movement termination (Litvak et al., 2012; Hirschmann et al., 2013). Second, evidence has amassed suggesting that the basal ganglia make a substantial contribution to the early phase of 
Table 1. Patient details

\begin{tabular}{|c|c|c|c|c|c|c|c|}
\hline Case & Age (years) & Disease duration (years) & UPDRS (III) off drug & UPDRS (III) on drug & First symptom & Surgical indication & Daily medication \\
\hline 1 & 57 & 6 & 21 & 7 & Left-sided bradykinesia & Motor fluctuations, dyskinesia & $\begin{array}{l}\text { Levodopa, } 750 \mathrm{mg} / \mathrm{d} \\
\text { Entacapone, } 1000 \mathrm{mg} / \mathrm{d}\end{array}$ \\
\hline 2 & 61 & 18 & 43 & 20 & Left hand tremor & Tremor & $\begin{array}{l}\text { Amantadine, } 200 \mathrm{mg} / \mathrm{d} \\
\text { Levodopa, } 750 \mathrm{mg} / \mathrm{d} \\
\text { Entacapone, } 1000 \mathrm{mg} / \mathrm{d}\end{array}$ \\
\hline 3 & 50 & 3 & 20 & 14 & Tremor & Tremor & $\begin{array}{l}\text { Apomorphine, } 4.5 \mathrm{mg} / \mathrm{h} \text {; Levodopa, } 600 \mathrm{mg} / \mathrm{d} \\
\text { Rasagiline, } 1 \mathrm{mg} / \mathrm{d} \\
\text { Ropinirole, } 24 \mathrm{mg} / \mathrm{d}\end{array}$ \\
\hline 4 & 65 & 15 & 51 & 21 & Left-hand tremor & Freezing, falls & $\begin{array}{l}\text { Amantadine, } 200 \mathrm{mg} / \mathrm{d} \\
\text { Levodopa, } 400 \mathrm{mg} / \mathrm{d} \\
\text { Ropinirole, } 12 \mathrm{mg} / \mathrm{d}\end{array}$ \\
\hline 5 & 42 & 9 & 56 & 12 & Loss of dexterity & Bradykinesia, dystonia & $\begin{array}{l}\text { Amantadine, } 400 \mathrm{mg} / \mathrm{d} \\
\text { Levodopa, } 600-1200 \mathrm{mg} / \mathrm{d}\end{array}$ \\
\hline 6 & 43 & 10 & 36 & 6 & & Motor fluctuations & $\begin{array}{l}\text { Levodopa, } 600 \mathrm{mg} / \mathrm{d} \\
\text { Ropinirole, } 2 \mathrm{mg} / \mathrm{d}\end{array}$ \\
\hline 7 & 53 & 7 & 25 & 5 & Loss of dexterity & Dyskinesia, bradykinesia & $\begin{array}{l}\text { Levodopa, } 800 \mathrm{mg} / \mathrm{d} \\
\text { Entacapone, } 800 \mathrm{mg} / \mathrm{d} \\
\text { Rasagiline, } 1 \mathrm{mg} / \mathrm{d}\end{array}$ \\
\hline 8 & 63 & 13 & 32 & 18 & Dragging of left leg & Stiffness & $\begin{array}{l}\text { Levodopa, } 700 \mathrm{mg} / \mathrm{d} \\
\text { Entacapone, } 1000 \mathrm{mg} / \mathrm{d} \\
\text { Ropinirole, } 8 \mathrm{mg} / \mathrm{d} \\
\text { Quetiapine, } 25 \mathrm{mg} / \mathrm{d} \\
\text { Clonazepam, } 0.5 \mathrm{mg} / \mathrm{d}\end{array}$ \\
\hline 9 & 64 & 11 & 22 & 9 & Right-sided tremor & Tremor, dyskinesia & $\begin{array}{l}\text { Levodopa, } 100 \mathrm{mg} / \mathrm{d} \\
\text { Rasagline, } 1 \mathrm{mg} / \mathrm{d} \\
\text { Ropinirole, } 10 \mathrm{mg} / \mathrm{d} \\
\text { Apomorphine, } 5 \mathrm{mg} / \mathrm{h} \\
\text { Propranolol, } 80 \mathrm{mg} / \mathrm{d}\end{array}$ \\
\hline 10 & 59 & 16 & 54 & 9 & Loss of dexterity & Dyskinesia, painful cramps & $\begin{array}{l}\text { Levodopa, } 100 \mathrm{mg} / \mathrm{d} \\
\text { Apomorphine, } 5 \mathrm{mg} / \mathrm{h} \\
\text { Rotigotine, } 4 \mathrm{mg} / \mathrm{d}\end{array}$ \\
\hline 11 & 60 & 13 & 40 & 13 & Left-hand tremor & Motor fluctuations & $\begin{array}{l}\text { Levodopa, } 700 \mathrm{mg} / \mathrm{d} \\
\text { Amantadine, } 300 \mathrm{mg} / \mathrm{d} \\
\text { Cabergoline, } 6 \mathrm{mg}\end{array}$ \\
\hline 12 & 69 & 10 & 34 & 12 & Shuffling gait & Motor fluctuations, bradykinesia & $\begin{array}{l}\text { Levodopa, } 800 \mathrm{mg} / \mathrm{d} \\
\text { Amantadine, } 100 \mathrm{mg} / \mathrm{d}\end{array}$ \\
\hline
\end{tabular}

UPDRS (III), Part III motor score of the United Parkinson's Disease Rating Scale. Three more patients were recorded but were excluded from final analysis because of an excessive number of invalid trials ( $>20 \%$ ). All patients had bilateral implantations. LFPs were recorded bilaterally for all patients except for patient 3 because of broken cables. This patient was left-handed and performed the task with the left hand, and LFPs from the right STN were recorded and used for analysis.

motor adaptation when large and consistent errors are experienced (Krebs et al., 1998; Krakauer et al., 2004; Seidler et al., 2006; Scheidt et al., 2012). Linking these first two strands of evidence is the observation that beta power in the striatum was modulated by the movement error and motor learning in rodents (Howe et al., 2011). Finally, the STN is a key node in the indirect pathways of the basal ganglia, particularly important in learning through negative associations (Frank et al., 2004). Movement errors may be processed as a nonrewarding negative feedback that signals the need to suppress unwanted movements and inappropriate motor programming.

Accordingly, we seek evidence for activity within the basal ganglia sensitive to movement prediction error and evidence that the STN-cortical connectivity is dynamically modulated by such error during the process of motor adaptation. To this end, we simultaneously recorded STN LFP activity and electroencephalographic (EEG) activity from patients with Parkinson's disease (PD) while they performed a joystick tracking task with and without perturbations in the form of visuomotor rotations.

\section{Materials and Methods}

Subjects. Fifteen patients with idiopathic PD (mean disease duration, 13 years; mean age, 62 years; range, $49-69$ years; all males) provided informed consent to take part in this study, which was approved by the local ethics committees. Patients underwent bilateral implantation of deep-brain stimulation (DBS) electrodes into the STN, as a prelude to high-frequency stimulation for the treatment of advanced PD with motor fluctuations and/or dyskinesia. Techniques to target and implant electrodes in the STN have been described previously (Foltynie and Hariz, 2010). Microelectrode recordings were not made during surgery. The permanent quadripolar macroelectrode used was model 3389 (Medtronic) featuring four platinum-iridium cylindrical surfaces. At the University College London Institute of Neurology, patients were operated on under general anesthesia, and lead location was confirmed with intraoperative stereotactic magnetic resonance imaging. At King's College Hospital, where implantation was performed with patients awake, effective stimulation was confirmed intraoperatively, and lead location was further confirmed with immediate postoperative stereotactic computerized tomography. Clinical details of the patients are given in Table 1. The patients all had normal or corrected-to-normal vision and showed $64.1 \pm 4.5 \%(p<0.001)$ improvement in the motor section of the Unified Parkinson's Disease Rating Scale on treatment with levodopa, indicating good responsiveness to this drug. All patients went on to have chronic monopolar stimulation, with, at 9-20 months after the implantation, the case used as the positive node and one channel (in 10 of 12 STNs) or two channels (in 2 of 12 STNs) used as the negative node. In all patients, the bipolar channel selected for analysis (see below) turned out to include the contact (10 STNs) or one of the two contacts (two STNs) used for stimulation. 
A

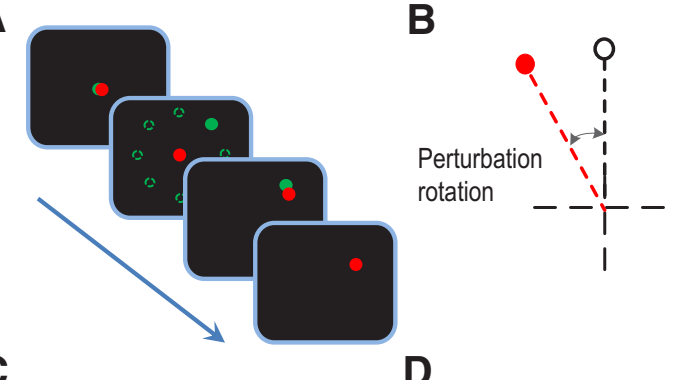

C

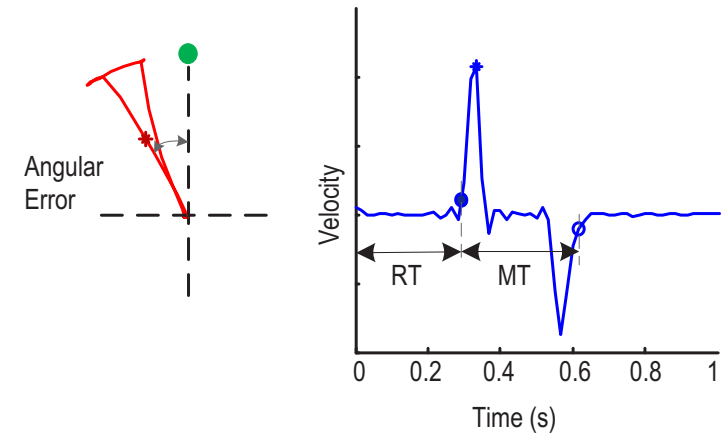

Figure 1. Experimental setup and measurements. $\boldsymbol{A}$, Experimental paradigm. $\boldsymbol{B}$, Perturbation was implemented as a rotation between the actual joystick position (in black) and its visual feedback (in red). C, Calculation of initial angular error in which the green circle indicates the position of the target, the red line is the joystick cursor trajectory, and the red star is the position of the cursor at the point of maximal velocity. D, Calculation of reaction time (RT) and movement duration (MT) in which time 0 is the timing of target position jump. The blue line is the velocity trajectory in one trial. The filled circle, star, and open circle indicate the timing of movement initiation, maximal velocity, and termination, respectively.

Experimental setup. Subjects were seated in front of a computer monitor and held a finger joystick with their dominant hand, which rested on a padded arm support. The position of the joystick was displayed on the computer monitor as a cursor in the form of a red circle that was $6 \mathrm{~mm}$ (0.6 visual degrees) in diameter. The target was a green circle $(6 \mathrm{~mm}$ diameter) displayed on the screen. Each trial started with the target (in green) and the cursor (in red) in the center of the monitor. Then the target jumped from the screen center to another position randomly selected from eight positions equally spaced around an invisible circle with a radius of $7.5 \mathrm{~cm}$ (6.1 visual degrees; Fig. 1A). The green target remained at its new position for $750 \mathrm{~ms}$ before returning to the center position, where the target stayed stationary for an additional $2.5 \mathrm{~s}$ before the next trial began, making the total intertrial interval $3 \mathrm{~s}$. Subjects were instructed to move the joystick when the green target jumped so as to shift the red cursor from the central start position to match the position of the green target in a rapid, discrete, and straight movement. The positions of both the red cursor and green target circles were continuously presented throughout the experiment. Perturbation was implemented by introducing an angular rotation between the red cursor and the actual movement of the joystick, so that the visual feedback of the joystick position was deviated from its actual position (Fig. 1B). Each subject completed three sessions of the task, in which the rotational perturbation was zero ("NoRoT" session), randomly changing in terms of size and direction from trial to trial ("RdmRot" session), or constant ("CnstRot" session). All subjects completed the three sessions in the fixed order and were not informed about the type of perturbations in advance. There was a short break of 2-3 min between each session. The rotational angles used in different sessions are shown in Figure $2 A$.

Data recording. Recordings were made when the patients were on their usual dopaminergic medication, 3-6 d postoperatively, while electrodes were externalized and before implantation of the pulse generator. The task was presented using open-source software (PsychoPy version 1.74). The timing of jumps in the green target and the positions of the cursor
A

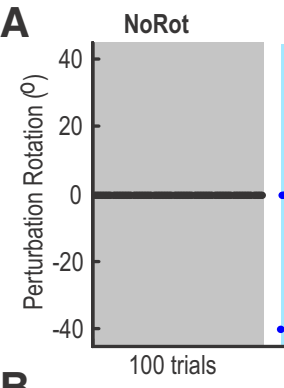

RdmRot

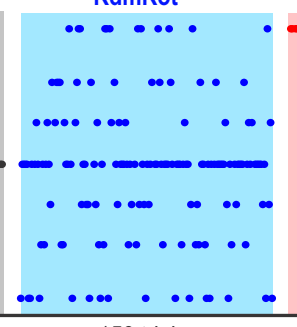

150 trials

B

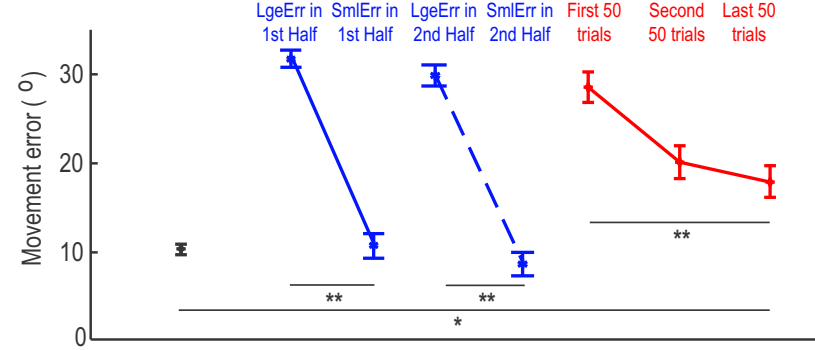

Figure 2. Group average behavioral results. $A$, Sessions with different types of perturbation: zero (NoRot), randomly changing across trials (RdmRot), or constant across trials (CnstRot). $\boldsymbol{B}$, Average absolute angular error in different experimental bins. When the perturbation was random, the trials were grouped into four bins: (1) large error trials in the first half; (2) small error trials in the first half; (3) large error trials in the first half; and (4) small error trials in the second half. When the perturbation was constant, movement error reduced with time. Circles and bars are mean \pm SEM. ${ }^{*} p<0.05,{ }^{* *} p<0.01$.

and target were sampled through PsychoPy at $100 \mathrm{~Hz}$ and sent to a digital-to-analog converter (U3; LabJack) to synchronize the cursor and target position with simultaneous EEG recordings.

STN local field potentials (LFPs) were recorded from the DBS electrodes. Simultaneously, scalp EEG was recorded from six channels over $\mathrm{FCz}, \mathrm{Cz}, \mathrm{CPz}, \mathrm{Oz}, \mathrm{C} 3$, and $\mathrm{C} 4$ according to the international 10-20 EEG system. It should be acknowledged that the precise location of the $\mathrm{C} 3$ and C4 electrodes may have been compromised (i.e., placed 1-2 cm off target) because of surgical wounds and dressings in this patient group. All signals were sampled at $2048 \mathrm{~Hz}$ and amplified using a TMSi Porti and its respective software (TMS International). The position of the joystick and the timing of the target jump were also recorded through the Porti amplifier. Before any analysis, monopolar recordings were downsampled to $250 \mathrm{~Hz}$, bandpass filtered between 0.5 and $100 \mathrm{~Hz}$, notch filtered at $50 \mathrm{~Hz}$, and converted to a bipolar montage between contacts so as to limit the effects of volume conduction from distant sources (three bipolar channels per STN side and three bipolar channels for the EEG recordings: $\mathrm{Fz}-\mathrm{Cz}, \mathrm{C} 3-\mathrm{Cz}$, and $\mathrm{C} 4-\mathrm{Cz}$ ). Individual trials of bipolar LFP and EEG signals were visually inspected before filtering, and trials with channels containing obvious artifacts attributable to facial muscle contraction, movement artifact, or poor conductance were marked as invalid and excluded from additional analysis.

Behavioral analysis. Data were analyzed using custom-written MATLAB (version R2012b; MathWorks) scripts. The position of the cursor was differentiated to calculate velocity, which was subsequently low-pass filtered through a Gaussian kernel with a window duration of 50 ms. The angular error was computed as the angle between the line connecting the start position and the cursor at the time of maximum velocity and the line connecting the start position and the target (Fig. 1C). Movement initiation was defined as the time when the joystick velocity crossed a threshold of three times the standard deviation (SD) of the signal (and its noise) at "rest" and sustained this speed for at least $100 \mathrm{~ms}$. Movement termination was the last time the hand velocity fell below the threshold for that trial (Fig. 1D). Thus, our measure of movement duration included all corrective movements, but our measurement of error was focused on the initial angular error of the cursor relative to the target before any corrective movements. Reaction time (interval between target 
jump and movement initiation), movement duration (interval between movement initiation and movement termination), and initial angular error were calculated for each individual trial and then averaged within subjects for each experimental condition. Because the focus of the study was to, as far as possible, examine the physiological functioning of STN in motor adaptation, we studied patients when they were on their normal dopaminergic medication and so they were as close to normal as possible in terms of performance in the task. In addition, trials with extra-long reaction time (more than mean $+2.5 \times \mathrm{SD}$ ) or initial movement error larger than $90^{\circ}$ or movement amplitude smaller than two-thirds of the target displacement were disregarded. Patients with $>20 \%$ invalid trials were excluded from additional analysis. This selection led to the exclusion of three patients. The $20 \%$ ( 3 of 15 ) patient exclusion rate reflects the relatively high cognitive and motor demands of the task and the feeling of fatigue and confusion some patients experience after surgery.

To evaluate how behavioral measurements changed in the task, trials in the constant rotation session were grouped into three bins according to execution order, with 46-50 trials for each bin. The trials in the random rotation session were first grouped into two bins according to execution order, and each bin was then divided into two bins according to error size relative to median error size. Thus, the trials in the random rotation session were grouped into four bins in total: (1) larger error trials in the first half of the session; (2) smaller error trials in the first half of the session; (3) larger error trials in the last half of the session; and (4) smaller error trials in the last half of the session, with 30-35 trials in each bin. All behavioral measurements were first calculated for each individual trial based on the time series of joystick positions and then averaged within experimental bins, before averaging across subjects.

Electrophysiological data analysis: frequency-time decomposition and intersite phase synchrony. The instantaneous power and phase of the bipolar channels in each trial were first calculated using the wavelet transform from 2 to $95 \mathrm{~Hz}$ with frequency resolution of $1 \mathrm{~Hz}$. A Morlet wavelet with 10 cycles for each frequency was used for the wavelet transform. An estimate of frequency band-specific power at each time point was defined as the squared magnitude of the resulting complex signal. Event-related change in power were calculated by normalizing the value of each time point against the mean value across the whole session and then subtracting 100 from each time point. Thus, a positive event-related change indicated a value larger than the overall average of the whole session and vice versa. The time-evolving cross-channel phase synchronization index (PSI) for each frequency was also evaluated across trials within each experimental bin and across a moving time window of $100 \mathrm{~ms}$ (Lachaux et al., 1999). This was performed because this index is not confounded by amplitude covariance.

Analysis of the LFP from the STN focused on the side of the STN that was contralateral to the hand used to perform the task. Of the three bipolar channels from each STN, the channel with the largest eventrelated power change in the beta band $(13-30 \mathrm{~Hz})$, i.e., the largest difference between the trough of event-related desynchronization during movement and the peak postmovement synchronization (ERS) in the beta band, was selected for additional analysis.

Partial directed coherence connectivity analysis. One of our primary aims was to explore the dynamics of cortical-STN connectivity in terms of functional coupling and causality in response to movement and motor error. To address this, we used multivariate autoregressive (MVAR) modeling and estimated the partial directed coherence (PDC), introduced by Baccalá and Sameshima (2001), as an index of the strength and direction of Granger causal information flow between LFP signals recorded from the STN and EEG signals recorded over the sensorimotor cortical area contralateral to the moving hand. As described below, one signal can be said to "Granger-cause" a second signal, if the inclusion of past observations of the first signal reduce the prediction error of the second signal in a linear regression model (relative to a model that only includes past observations of the second signal). Therefore, note that Granger causal information flow need not imply direct connectivity, for example, in the form of the hyperdirect pathway from the frontal cortex to the STN. It can also capture indirect connectivity, as for example from the STN to cortex mediated by globus pallidus and thalamus. Moreover, this measure cannot distinguish the above from common drives with different time lags to, for example, the STN and cortex, and so results must be interpreted in the context of known anatomy and additional physiological data. Still, Granger causality has proved informative in a number of investigations of effective connectivity in the CNS (Zavala et al., 2013; Herrojo Ruiz et al., 2014; Nakhnikian et al., 2014).

The MVAR modeling is strictly based on the principle of Granger causality and therefore does not take into account zero-lagged or instantaneous influence:

$$
\left[\begin{array}{c}
x_{1}(n) \\
\cdot \\
\cdot \\
x_{N}(n)
\end{array}\right]=\sum_{r=1}^{p} A_{r}\left[\begin{array}{c}
x_{1}(n-r) \\
\cdot \\
\cdot \\
x_{N}(n-r)
\end{array}\right]+\left[\begin{array}{c}
w_{1}(n) \\
\cdot \\
\cdot \\
w_{N}(n)
\end{array}\right]
$$

where $\left[x_{1}, \ldots, x_{N}\right]$ is a vector of $N$ stationary stochastic processes, $p$ is the model order, i.e., the number of previous time points used to predict the present value of each process, $A_{r} \in R^{N \times N}$ is the regression coefficient matrix and $A_{r}(i, j)$ represents the linear prediction effect of $x_{j}(n-r)$ on predicting $x_{i}(n)$. $\left[w_{1}, \ldots, w_{N}\right]$ are independent white-noise processes describing the modeling residuals. According to Granger causality, the time series $x_{j}(n)$ can be said to Granger-cause another time series $x_{i}(n)$, if the prediction error of $x_{i}(n)$ can be reduced by including past observations of $x_{j}(n)$, i.e., if the coefficients of the history of the first signal are not uniformly zero $\left[A_{r}(i, j) \neq 0\right.$ for some $\left.r\right]$.

The PDC was derived from the spectral representation of the entries of the regression coefficient matrix $\left(A_{r}\right)$ based on MVAR modeling (Kamiński and Blinowska, 1991; Baccalá and Sameshima, 2001):

$$
\begin{aligned}
\left|\pi_{i \leftarrow j}(\omega)\right|=\frac{\left|\bar{A}_{i j}(\omega)\right|}{\sqrt{\sum_{k}\left|\bar{A}_{i k}(\omega)\right|^{2}}} \text { with } \\
\bar{A}_{i j}(\omega)=\left\{\begin{array}{l}
1-\sum_{r=1}^{p} A_{r}(i, j) e^{-i 2 \pi \omega r}, \text { if } i=j \\
-\sum_{r=1}^{p} A_{r}(i, j) e^{-i 2 \pi \omega r}, \text { otherwise }
\end{array} .\right.
\end{aligned}
$$

This measurement of PDC $\left[\pi_{i \leftarrow j}(\omega)\right]$ is equal to zero when $A_{r}(i, j)$ is uniformly zero and can be viewed as a frequency-domain measure for multivariate Granger causality.

A Granger causality connectivity analysis (GCCA) tool box (Seth, 2010) was used to preprocess the data, check the covariance stationarity of the signals, search for optimal modeling order for the MVAR, calculate the MVAR matrix, and perform model validation by checking the whiteness and independence of the estimated model residuals.

To minimize nonstationarities across trials in each experimental condition, data from each trial were first zero-meaned by subtracting the mean voltage of that trial from each time point and then ensemble zeromeaned by subtracting the ensemble mean from each time point (Ding et al., 2000). The ensemble mean is determined by averaging the values for each variable at each time point across trials within each experimental condition. Therefore, the connectivity analysis reported here is based on the induced activity with the across-trial average removed. Covariance stationarity was checked using the augmented Dickey Fuller test and the Kwiatkowski-Phillips-Schmidt-Shin (KPSS) test ("cca_check_cov_stat" and "cca_kpss" functions in the GCCA tool box, respectively). Models with model order between 2 and 50 were compared, and the appropriate MVAR model order was determined using the Bayesian information criterion. The MVAR matrix was calculated for each experimental condition and then converted into the spectral domain, before the PDC was calculated and used to determine the directionality of STNEEG interactions.

Statistical analysis. Grand averages of behavioral and electrophysiological measurements for different experimental conditions were calculated after deriving each of these variables from each individual trial made by a subject and then calculating averages across trials for that subject, before averaging across study participants. For electrophysiological measurements, significant differences from baseline for each condition were first 
evaluated using one-sample $t$ tests. Differences between conditions were assessed with ANOVA. Means \pm SEMs are presented throughout the text, unless otherwise specified.

Statistical analyses were performed in SPSS Statistics 19 (SPSS). Kolmogorov-Smirnov tests were applied to confirm that behavioral measures and LFP data were normally distributed, before additional parametric testing. When Mauchly's test of sphericity was significant $(p<0.05)$ in repeated-measures ANOVAs, Greenhouse-Geisser corrections were applied. Multiple comparisons were corrected for using the false discovery rate procedure (Curran-Everett, 2000), and only those $p$ values remaining significant after this procedure are given.

\section{Results}

\section{Behavioral results}

In the session in which a constant rotational perturbation was introduced, trials were grouped into three experimental bins according to execution order. Subjects made progressively less movement error as bin number increased $\left(F_{(2,22)}=43.069, p<\right.$ 0.001 ; Fig. $2 B$ ), indicating a significant adaptation over time. The absolute movement error reduced from $30.9 \pm 1.9^{\circ}$ in the first bin of 50 trials to $17.8 \pm 1.8^{\circ}$ in the last $\left(t_{(11)}=7.391, p<0.001\right)$. The movement error was stable in the last bin of adaptation, as confirmed by similar movement errors between the first half and the second half of this bin $\left(t_{(11)}=1.232, p=0.244\right)$, although the average error in the last bin was still larger than that when there was no perturbation rotation $\left(17.8 \pm 1.8^{\circ}\right.$ compared with $10.9 \pm$ $\left.1.0^{\circ}, t_{(11)}=3.60, p=0.004\right)$. The mean degree of adaptation, defined as the difference between the average errors in the first bin and the last bin, was $12.2 \pm 1.3^{\circ}$ across subjects.

Other movement parameters, including reaction time and movement duration, were not modulated by the time spent in a session or by different types of perturbations, as confirmed by a lack of main effect of execution bin (early or late in each session: $F_{(4,44)}=0.798, p=0.533$ for reaction time; $F_{(4,44)}=1.059, p=$ 0.388 for movement duration), perturbation type (none, random, or constant: $F_{(1,11)}=0.159, p=0.698$ for reaction time; $F_{(1,11)}=0.625, p=0.446$ for movement duration), or interaction between execution bin and perturbation type $\left(F_{(4,44)}=2.334\right.$, $p=0.172$ for reaction time; $F_{(4,40)}=0.429, p=0.787$ for movement duration). The average reaction times and movement durations were $472 \pm 17$ and $612 \pm 43 \mathrm{~ms}$, respectively, across subjects.

The particular value of the random perturbation session, in which perturbations randomly changed in both direction and size across trials without forewarning of randomness, was that movement error was dissociated from the time spent on the task. In this session, all trials were grouped into four experimental bins according to error amplitude and when the error was experienced (see Materials and Methods). Two-way repeated-measures ANOVA applied on the average movement errors in these four bins with factors of error size and time spent in the task (first or last half of the session) identified a significant effect of error size $\left(F_{(1,11)}=175.173, p<0.001\right)$ and lack of effect of time spent in the task $\left(F_{(1,11)}=0.185, p=0.675\right)$. This suggests that there was no difference in the movement errors between the first half and the last half of the session because of the randomness of the perturbation. However, despite the fact that the errors were constant throughout the session, the contextual salience of the movement error changed over time. With more time spent on the task, the randomness of the error became more obvious and the salience of the error reduced. This change in the perceived salience of movement errors was manifested in the change in reaction time in the trial after a trial with large errors: paired $t$ tests showed that there was a slowing down in the reaction time after large errors compared with that after small error trials in the first half of the session $\left(489 \pm 24 \mathrm{~ms}\right.$ compared with $467 \pm 22 \mathrm{~ms}, t_{(11)}=$ $3.347, p=0.005)$ but not in the last half of the session $(469 \pm 26$ ms compared with $\left.466 \pm 25 \mathrm{~ms}, t_{(11)}=0.326, p=0.749\right)$. Thus, large errors were only salient, as judged by their effect on the subsequent trial, in the first half of the random perturbation session.

\section{Postmovement beta resynchronization changes with movement errors and contextual salience in the STN LFP and cortical EEG}

Our principal goal was to establish whether the STN and, in particular, the effective connectivity between the STN and cerebral cortex, was involved in the system processing the contextual significance of movement errors manifest through the modulation of the cortical ERS during visuomotor adaptation (Tan et al., 2014). To this end, we set out to both confirm that our patients had a similar pattern of cortical ERS reactivity to that reported previously in healthy young subjects during adaptation (Tan et al., 2014) and demonstrate a similar reactivity within the STN. Simultaneous cortical and subcortical recordings showed that power decreased during movement over a broad beta frequency band (13-30 Hz) in bipolar EEG channels overlying mesial frontal $(\mathrm{FzCz})$ and contralateral sensorimotor cortical areas $(\mathrm{C} 3 \mathrm{Cz})$ and in bipolar STN LFP channels contralateral to the moving hand. This was followed by a rebound increase in power after movement termination, as shown in Figure $3 A$. These are well recognized features of STN and cortical reactivity (Litvak et al., 2012; Hirschmann et al., 2013). Also of interest was the shortlatency increase in theta power after movement onset in both STN and $\mathrm{FzCz}$ but not $\mathrm{C} 3 \mathrm{Cz}$ (Fig. 3A). However, here, we focus on activity in the beta band $(13-30 \mathrm{~Hz})$. The first novel observation in this band was that the postmovement beta resynchronization in both the STN and $\mathrm{C} 3 \mathrm{Cz}$, but not the $\mathrm{FzCz}$, increased as trial number increased during the constant perturbation session, suggesting either a dependency on error (which was greatest early in the session) or time on task (Fig. 3B). Thus, the postmovement beta resynchronization in the STN and C3Cz in the last bin of the session with constant perturbation was increased compared with that in the first bin $(23.78 \pm 3.53 \%$ compared with $6.72 \pm 4.01 \%$, $t_{(11)}=2.741, p=0.019$ in STN; and $8.35 \pm 1.63 \%$ compared with $2.61 \pm 1.40 \%$ for $\left.\mathrm{C} 3 \mathrm{Cz}, t_{(11)}=3.427, p=0.005\right)$. Because there was no difference in the beta rebound with time spent on task in the session that contained no perturbations (data not shown), the observed increases were most likely attributable to a dependency on error.

During the session when perturbations randomly changed in both direction and size from trial to trial, movement error was dissociated from the time spent on the task, whereas the contextual salience of the movement error changed with time spent on the task. With more time spent on the task, the randomness of the error became more obvious and the salience of the error reduced, as reflected in the loss of post-error slowing (see behavioral results). In this session, the postmovement beta synchronization in the $\mathrm{STN}$ and $\mathrm{C} 3 \mathrm{Cz}$ also was suppressed after trials with large errors but only in the first half of the session (Fig. $3 C, D$ ). Threeway repeated-measures ANOVA with factors of error size (large or small), time spent in the task (first or last half), and channels (STN, $\mathrm{C} 3 \mathrm{Cz}$, or $\mathrm{FzCz}$ ) was performed on the average postmovement beta ERS. This identified a significant effect of error $\left(F_{(1,11)}\right.$ $=10.688, p=0.007)$, a significant interaction between error and time in the task $\left(F_{(1,11)}=9.621, p=0.010\right)$, and a significant three-way interaction $\left(F_{(2,22)}=3.946, p=0.034\right)$. Paired $t$ tests 
A
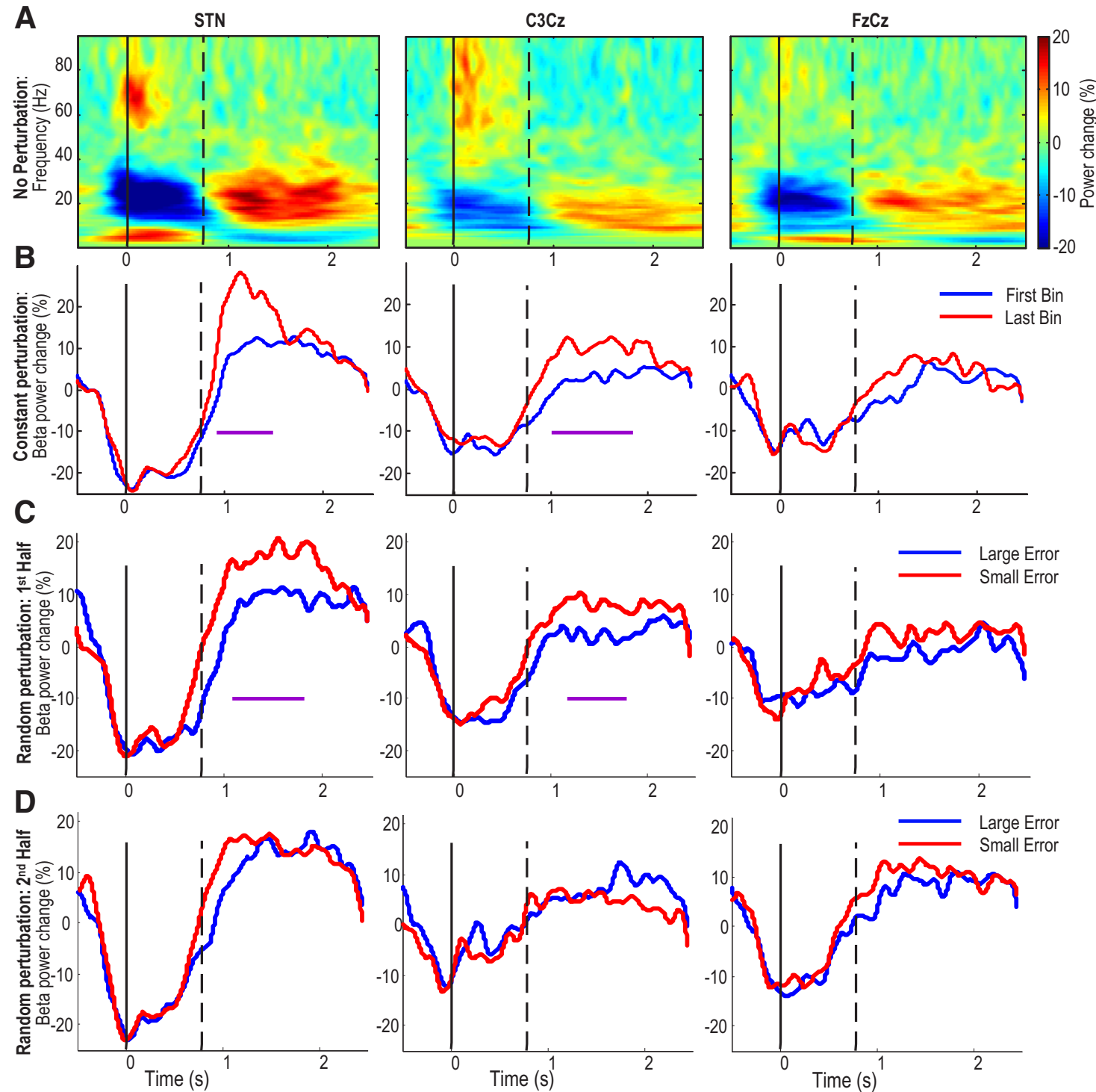

Figure 3. Group average power change with movement status and movement errors. $A$, The event-related power change in STN, C3Cz, and FzCz, averaged across all trials in session with no perturbation. Vertical solid and dashed lines show the timings of movement onset and movement offset, respectively. $\boldsymbol{B}$, In the session with constant perturbations, beta ERS after movement offset was lower during the first bin compared with the last bin, in STN and C3Cz. In the session with random perturbations, postmovement beta ERS in the STN and C3CZ were modulated by the size of error but only in the first half of the session $(\boldsymbol{C}$ ) and not in the last half of the session (D). Purple lines in $\boldsymbol{B}-\boldsymbol{D}$ show when the difference was significant with $p<0.05$.

confirmed that the beta synchronization in the STN after large errors was lower than that after small errors in the first half, but there is no effect of error size on beta ERS in the second half of the session. A similar effect was also found for the beta $\mathrm{ERS}$ at $\mathrm{C} 3 \mathrm{Cz}$ (Fig. 3C,D).

These results suggest an effect of the amplitude of movement errors and of the contextual salience of movement errors on the modulation of the postmovement beta ERS in STN and over sensorimotor cortex, similar to that observed over the $\mathrm{C} 3 \mathrm{Cz}$ in young healthy subjects (Tan et al., 2014).

Postmovement cortex-STN connectivity in beta band depends on cortical region and is asymmetric between STN and $\mathrm{C} 3 \mathrm{Cz}$

Because beta activity increased after movement offset in STN and in $\mathrm{C} 3 \mathrm{Cz}$ and $\mathrm{FzCz}$ and the postmovement beta ERSs in both $\mathrm{C} 3 \mathrm{Cz}$ and STN were modulated by movement error and its contextual salience, we investigated the connectivity between STN and dif- ferent cortical areas. The intersite PSI was used to assess functional connectivity that was independent of power changes. This demonstrated a frequency-specific and movement statusdependent pattern in the intersite PSI in unperturbed movements (Fig. $4 A, B$ ). A two-way repeated-measures ANOVA with factors of sites (STN-FzCz or STN-C3Cz) and movement status (during movement or postmovement with time window length of $600 \mathrm{~ms}$ each) was applied to the average PSI in the beta band. This identified a significant interaction between sites and movement status $\left(F_{(1,11)}=9.228, p=0.010\right)$. Paired $t$ tests showed that the beta-band PSI between STN and FzCz remained low in both movement states $(0.076 \pm 0.005$ during movement compared with $0.080 \pm 0.006$ after movement, $t_{(11)}=-0.364, p=0.722$ ). In contrast, the beta-band PSI between STN and C3Cz was significantly increased after movement compared with that during movement $\left(0.136 \pm 0.013\right.$ compared with $0.076 \pm 0.009, t_{(11)}=$ $5.679, p<0.001)$. The peak postmovement STN-C3Cz PSI in the beta band was not correlated with the peak postmovement beta 
A
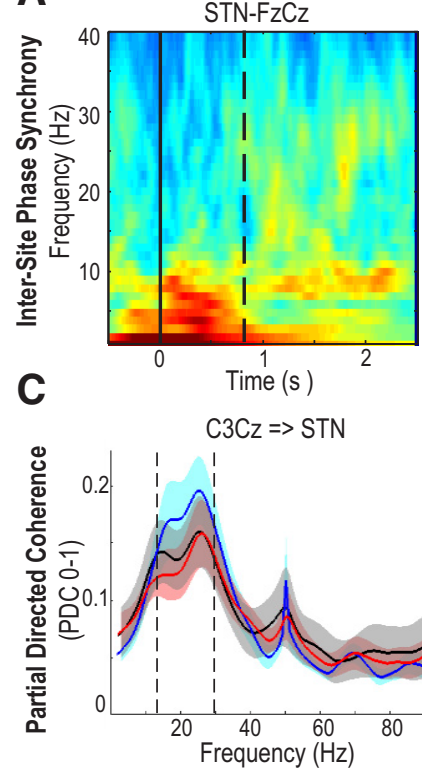

B $\quad$ STN-C3CZ

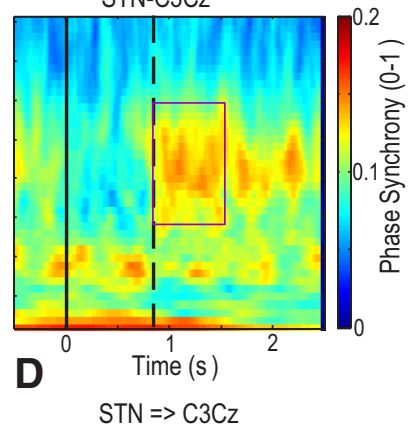

No perturbation

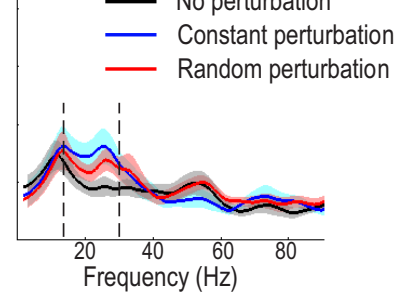

Figure 4. Group intersite phase synchrony and PDC between the cortex and STN. Intersite PSI showed different patterns of connectivity between the STN and $\mathrm{C} 3 \mathrm{CZ}(\boldsymbol{A})$ from that between $\mathrm{STN}_{\mathrm{N}} \mathrm{Fz}_{\mathrm{Z}}(\boldsymbol{B})$ in unperturbed movements. There is increased phase synchrony between the STN and C3Cz in the beta band after movement offset, highlighted by the purple square. Vertical solid and dashed lines in $\boldsymbol{A}$ and $\boldsymbol{B}$ indicate the timing of movement onset and offset, respectively. $C, D, P D C$ analysis on postmovement data showed that the PDC from C3CZ to STN was dominant, independent from the type of perturbation. In Cand D, the thick solid lines show the average across subjects, shaded areas indicate $S E$, and vertical dashed lines show the beta-band region.

power increase in either the STN $(r=0.280, p=0.404)$ or $\mathrm{C} 3 \mathrm{Cz}$ $(r=0.217, p=0.454)$ across subjects, confirming that the increased connectivity observed after movement between the STN and $\mathrm{C} 3 \mathrm{Cz}$ was not directly related to the increased beta power at the two levels.

The directionality of this increased coherence between STN and the sensorimotor cortical area $(\mathrm{C} 3 \mathrm{Cz})$ during the postmovement time window was evaluated using MVAR modeling and PDC analysis. This analysis was performed for different experimental sessions separately, with data from the postmovement window (600 ms duration after movement offset) from all individual trials as independent realizations of the same stationary process. This identified that the PDC from C3Cz to STN dominated in the beta band, independent from the type of perturbations in different experimental sessions (Fig. 4C,D). Two-way repeated-measures ANOVA with factors of direction of the connectivity ( $\mathrm{C} 3 \mathrm{Cz}$ to STN or STN to $\mathrm{C} 3 \mathrm{Cz}$ ) and type of perturbation (none, constant, or random: all trials) on the postmovement PDC averaged between 13 and $30 \mathrm{~Hz}$ confirmed significant effects of direction $\left(F_{(1,11)}=34.90, p<0.001\right)$ but did not show the effect of type of perturbation $\left(F_{(2,22)}=0.234, p=0.793\right)$ or interaction between perturbation type and direction $\left(F_{(2,22)}=\right.$ $2.391, p=0.111)$. In the postmovement time window, $\mathrm{C} 3 \mathrm{Cz}$-toSTN PDC (0.165 \pm 0.019$)$ was significantly larger than STN-to$\mathrm{C} 3 \mathrm{Cz}$ PDC $\left(0.059 \pm 0.009, t_{(11)}=5.908, p<0.001\right)$, suggesting that the primary direction of information flow during this window was from $\mathrm{C} 3 \mathrm{Cz}$ to the STN. This asymmetry was validated by the same PDC analysis applied to the time-reversed data (Haufe et al., 2013) from the session with no perturbation. This confirmed causal information flow in the reversed direction between data from STN and time-reversed C3Cz, with beta PDC from
A

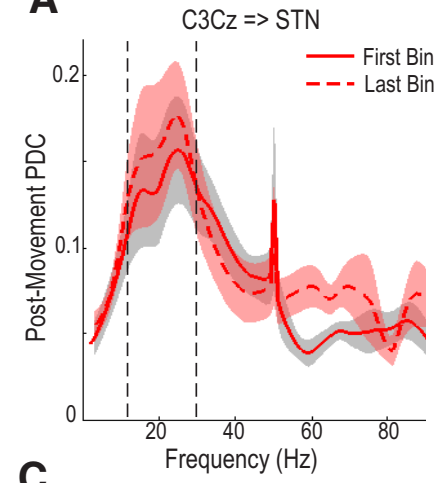

C

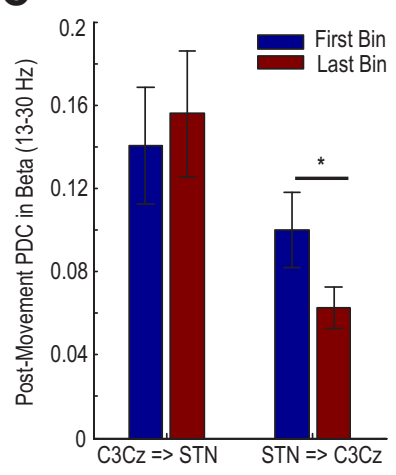

B
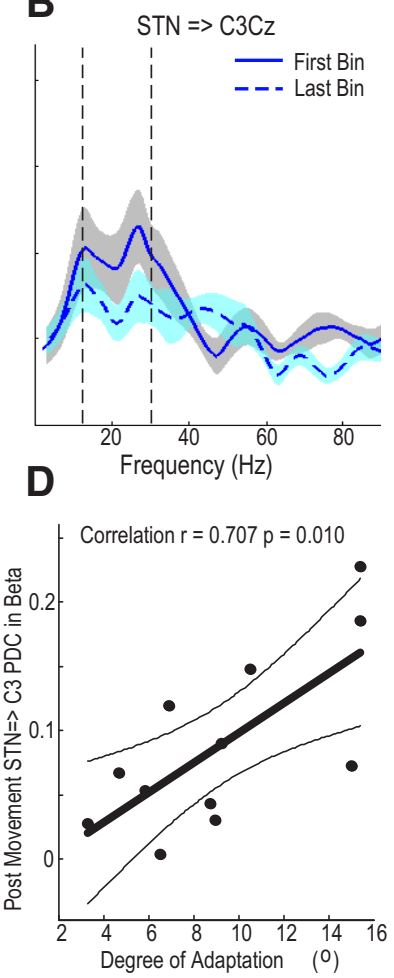

Figure 5. Group postmovement STN-to-C3CZ PDC was modulated by adaptation during trials with a constant perturbation. $\boldsymbol{A}$, Postmovement PDC from C3Cz to STN was similar in the first and last bins of adaptation in the beta band (shown by the dashed vertical lines). The peak around $50 \mathrm{~Hz}$ is caused by line noise. $\boldsymbol{B}$, Postmovement PDC from the STN to $\mathrm{C} 3 \mathrm{Cz}$ was increased in the beta band during the first bin of adaptation. $\boldsymbol{C}$, ANOVA and post hoc $t$ test identified significantly higher beta-band STN-to-C3CZ PDC in the first bin compared with the last bin during adaption. ${ }^{*} p<0.05$. D, The postmovement STN-to-C3CZ PDC in the first bin correlated with the degree of adaptation achieved across subjects. The thick black line is the result of linear regression. Thin black lines are the $95 \%$ confidence limits.

STN to time-reversed $\mathrm{C} 3 \mathrm{Cz}$ significantly larger than that from time-reversed $\mathrm{C} 3 \mathrm{Cz}$ to STN $(0.119 \pm 0.013$ compared with $\left.0.039 \pm 0.010, t_{(11)}=5.638, p<0.001\right)$. This safety check ensures that any PDC asymmetry is not generated by differing signal-to-noise ratios between the signals.

\section{Balance of information flow between the cortex and STN changes with adaptation}

Next, we investigated whether there might be a change in the direction of information flow in the beta band during the postmovement phase of constant perturbation trials, as adaptation developed. To this end, MVAR modeling and PDC analyses between STN and C3Cz were applied to the data from different trial bins. During the last execution bin when the movement errors reached asymptote, the coupling in the beta band was dominated by information flow from the cortex, and the information flow from the STN was negligible, similar to baseline movements when there was no perturbation. In contrast, during the first execution bin of the adaptation phase, there was increased information flow from the STN to $\mathrm{C} 3 \mathrm{Cz}$ in the beta band (Fig. $5 B$ ). Two-way repeated-measures ANOVA with factors of execution bin (first or last) and direction $(\mathrm{C} 3 \mathrm{Cz}$ to $\mathrm{STN}$ or $\mathrm{STN}$ to $\mathrm{C} 3 \mathrm{Cz}$ ) identified a significant interaction between the two factors $\left(F_{(1,11)}=14.433, p=0.003\right.$; Fig. $\left.5 C\right)$ but a lack of a main effect of direction $\left(F_{(1,11)}=4.637, p=0.054\right)$ or execution bin $\left(F_{(1,11)}=\right.$ 

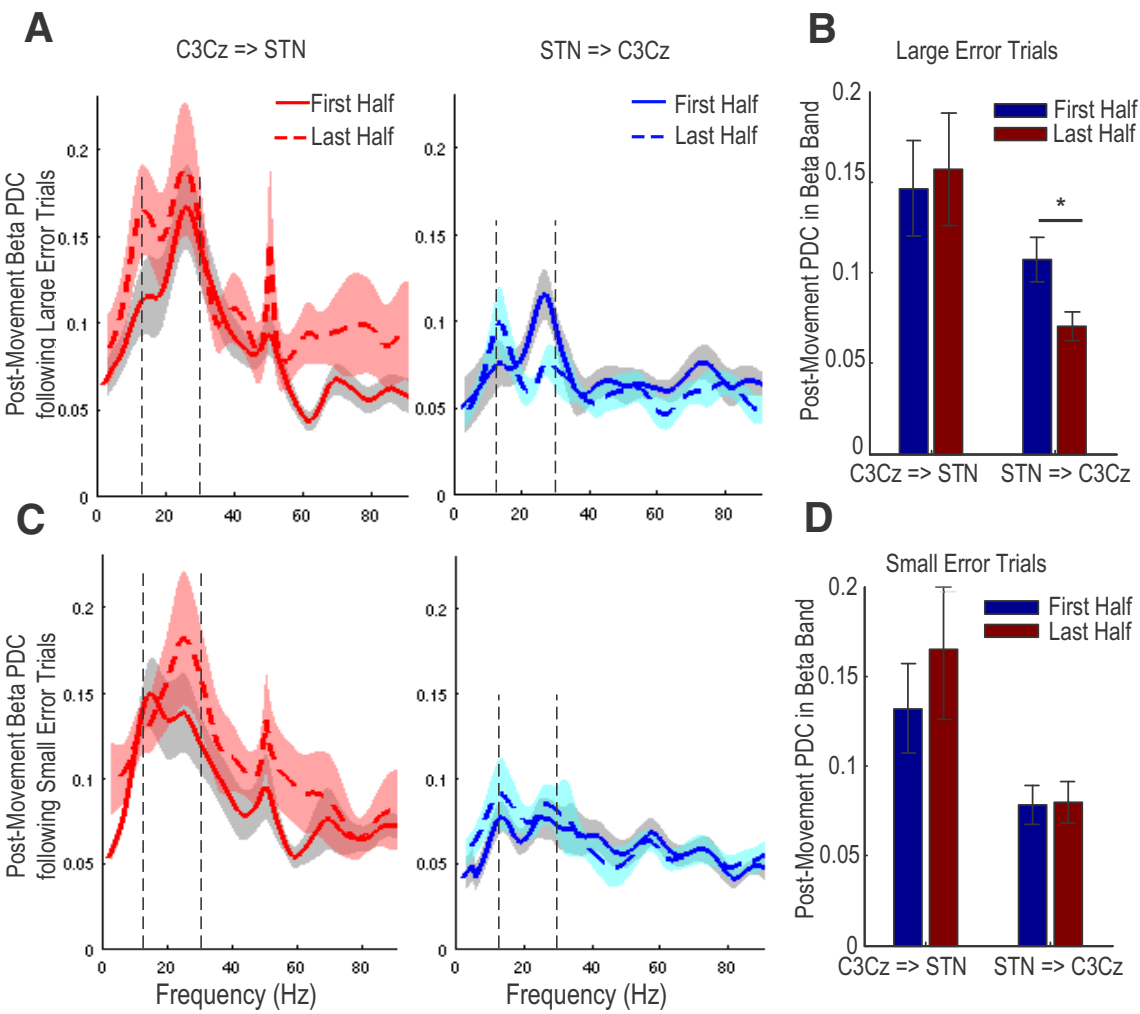

two-way ANOVA of STN-to-C3Cz PDC in the broad beta band with factors of error amplitude (large or small) and execution order (first or last half of the session) identified a significant interaction between error and execution order $\left(F_{(1,11)}=\right.$ 9.411, $p=0.011)$. Paired $t$ tests showed that STN-to-C3Cz information flow was larger after large errors experienced in the first half of the session $(0.108 \pm 0.013)$ than in the last half of the session $(0.063 \pm$ $\left.0.005, t_{(11)}=3.360, p=0.006\right)$ and also significantly larger than STN-to-C3Cz information flow after small errors $(0.077 \pm$ $\left.0.010, t_{(11)}=2.775, p=0.018\right)$. A similar ANOVA applied on the information flow from $\mathrm{C} 3 \mathrm{Cz}$ to STN failed to identify any effects of error $\left(F_{(1,11)}=0.786, p=0.394\right)$ or execution order $\left(F_{(1,11)}=1.446, p=\right.$ $0.254)$ or their interaction $\left(F_{(1,11)}=0.667\right.$, $p=0.431)$. Accordingly, only information flow from STN to $\mathrm{C} 3 \mathrm{Cz}$ was modulated by the contextual salience of errors.

\section{Discussion}

We investigated spectral change in the STN and cortical EEG and effective connectivity between the STN and EEG in PD patients while they performed a joystick-based motor adaptation task on their normal dopaminergic medication. We found that, after movement offset, there was a beta-band activity in both local STN LFP and sensorimotor cortical EEG power affected by both motor

$2.314, p=0.156)$. Post hoc analysis with paired $t$ tests showed that there was no effect of adaptation on the C3Cz-to-STN information flow. However, STN-to-C3Cz beta information flow was significantly increased during the first 50 trials of adaptation compared with the last 50 trials $(0.100 \pm 0.028$ vs $0.063 \pm 0.010$, $\left.t_{(11)}=4.265, p=0.001\right)$. Importantly, the STN-to-C3Cz information flow in the first 50 trials correlated with the degree of adaptation (difference between the average error in the last bin and the first bin) that was achieved across subjects $\left(r^{2}=0.500\right.$, $p=0.010$; Fig. $5 D$ ). A similar ANOVA applied to the beta-band FzCz-to-STN PDC showed no significant effect of direction $\left(F_{(1,11)}=2.037, p=0.181\right)$ or interaction between movement and direction $\left(F_{(1,11)}=0.364, p=0.559\right)$.

\section{STN-to-C3Cz information flow increased after large errors but only when this is salient}

During the session when perturbations randomly changed in both direction and size from trial to trial, the contextual salience of the movement error changed with time spent on the task, as reflected in the loss of post-error slowing and lack of beta ERS modulation in the last half of the trials from the session (see behavioral and beta ERS results). In this session, the STN-to$\mathrm{C} 3 \mathrm{Cz} \mathrm{PDC}$ in the beta band after trials with large errors also increased but only in the first half of the session (Fig. $6 A, B$ ). In contrast, after movements with large errors in the second half of the session and after the movements with small errors, the information flow between the STN and C3Cz was more heavily dominated by the C3Cz-to-STN PDC in the beta band, similar to the situation after unperturbed movements (Fig. 6C,D). Repeated error magnitude and its contextual saliency. Postmovement beta activities at the two sites were coupled, and the relative directionality of information flow (PDC) changed during visuomotor adaptation. Information flow from the STN to the sensorimotor cortex increased after large, salient errors, and the degree of increase correlated with motor-command adjustment across subjects. Such activity suggests an interaction between the STN and the sensorimotor cortex that is involved in the evaluation of the salience of movement errors, both in terms of their size and context and/or in the modifying of motor responses in the light of this.

Other studies have furnished evidence that activity in the STN and its downstream target, the globus pallidus interna, may be modulated by error and by the related phenomenon of conflict. However, previous research on error monitoring has primarily focused on decision making and action selection, in which the evaluation of the performance is discrete and the error concerns inappropriate action selection. In addition, activities reported in previous studies have different characteristics: (1) they occur before completion of the response; (2) are mediated by oscillations in the theta frequency band; (3) are preferentially coupled to the mesial frontal cortex; and (4) are not modulated by performance history (Zavala et al., 2013; Cavanagh et al., 2014; Herrojo Ruiz et al., 2014). Accordingly, the postmovement beta activity within and between the STN and sensorimotor cortex investigated here is likely to represent a distinct process. 


\section{Beta oscillations in the corticobasal ganglia network in movement error processing}

We have showed previously that the postmovement beta synchronization over the sensorimotor cortex was reduced after task-relevant movement errors, and we speculated that the relative decrease in postmovement beta ERS allows for more flexibility and capacity for information coding and thereby revision of motor plans (Brittain and Brown, 2014; Tan et al., 2014). Here we showed that beta-band activity in the STN LFP reacted to movement errors in a similar manner. Beta activity in the STN and cerebral cortex has been hypothesized to promote the status quo (Brown, 2007; Engel and Fries, 2010). Accordingly, the attenuation of the postmovement beta ERS in trials with large errors might facilitate changes in motor programming, especially when past movement errors have shown little variability.

Beta oscillations recorded from the STN and sensorimotor cortical areas are coherent (Cassidy et al., 2002; Williams et al., 2002), and, like beta power in the STN, coherence has been found to be attenuated by movement (Lalo et al., 2008; Litvak et al., 2012), the administration of levodopa (Williams et al., 2002; Hirschmann et al., 2013), and DBS (Kühn et al., 2008). It is, as yet, unclear as to whether such coherence is pathological or physiological (Litvak et al., 2012). Inter-regional coherence in the beta band may differ in function from local synchronization in the same frequency band (Silberstein et al., 2005), and, indeed, these were uncorrelated in our paradigm. We observed increased coherence between sensorimotor cortical areas and the STN in the beta band after ballistic goal-directed movements when the patients were on their normal medication, and our results suggest that the coupling between these two structures may be involved in evaluating the outcome of the previous movement according to its contextual relevance.

In particular, we showed that the STN-to-sensorimotor cortex beta drive was modulated by salient movement errors. The STNto-sensorimotor cortex beta drive increased after large errors but only when the errors were contextually salient, as in adaptation to constant perturbations or, with random perturbations, before randomness was apparent. When the unpredictability of the movement error became manifest later on in time in the random perturbation session, its significance with respect to action reprogramming was reduced, and the information flow from the STN fell off.

What might be the specific role of the STN drive to the sensorimotor cortex early during visuomotor adaptation? We posit that this STN-to-cortex beta drive paradoxically acts to limit the local cortical synchronization after movement prediction error, thereby facilitating revision of the last motor program. The functional importance of the STN-to-cortex information flow in the beta band was confirmed by its correlation with the degree of adaptation achieved across subjects. In addition, the notion that basal ganglia beta activity could, under some circumstances, paradoxically degrade local cortical synchronization in the beta band has a precedent in the suppression of corticomuscular beta activity and of the cortical beta ERS when subcortical beta activity is elevated in PD patients withdrawn from dopaminergic medication or during discontinuation of DBS (Brown et al., 2001; Marsden et al., 2001; Salenius et al., 2002; Devos et al., 2004). Nevertheless, the hypothesis that STN-to-cortex beta drive might contribute to the attenuation of the cortical beta-band ERS after motor errors remains speculative and requires additional testing.

\section{BG in motor learning}

The results presented here are consistent with models of motor learning that propose that the basal ganglia contribute to early learning processes, regardless of the type of learning (Doyon and Benali, 2005; Doyon et al., 2009). However, previous models have focused on the potential role of the basal ganglia, and the striatum in particular, in learning the costs (effort required) and rewards associated with the execution of a motor action (Shadmehr and Krakauer, 2008; Turner and Desmurget, 2010; Liljeholm and O'Doherty, 2012). Midbrain dopamine neurons are hypothesized to encode reward prediction error (Houk et al., 1995; Nakahara et al., 2004; Bayer and Glimcher, 2005), and this error signal can be used for learning rewarding stimulus-action associations (Graybiel et al., 1994; Reynolds et al., 2001). Furthermore, dopamine-containing neurons in the basal ganglia have been shown to tune their sensitivity according to reward uncertainty (Tobler et al., 2005) and to code reward prediction error in a context-dependent manner (Nakahara et al., 2004).

More specifically, it has been proposed that learning positive associations (rewarding) and negative (nonrewarding) associations can be mediated by different pathways in the corticobasal ganglia network, with the positive association learning controlled by the direct Go pathway, which bypasses the STN, and negative associations by the indirect No-Go pathway, which involves the STN (Frank et al., 2004). Consistent with involvement of the indirect pathway in the processing of negative associations, our data suggest that the STN contributes to the early learning phase in visuomotor adaptation as part of the network that recognizes movement prediction errors in a context-dependent manner and contributes to post-error motor adjustment. Information flow from the STN to the cortex in the beta band might then serve to promote change at the cortical level so that motor programs are recalibrated in the face of large and salient errors.

\section{Potential limitations and concluding remarks}

The current study has some major limitations. First, our study participants were necessarily patients with $\mathrm{PD}$, so inferences regarding normal functioning must be circumspect (Williams et al., 2002). However, all data presented here were recorded when the patients were on their normal dopaminergic medication in an attempt to approximate physiological functioning as closely as possible. In line with this, the patients presented here showed significant reduction of error when a constant perturbation was applied as a sign of adaptation. Second, we have not defined the relative contributions of the basal ganglia and cerebellar system in visuomotor adaptation, whereas the interaction of the two is thought to be critical for establishing new motor behaviors (Doyon et al., 2009). Third, analyses were performed on binned data (i.e., first block of 50 trials vs last block of 50 trials, or the first half of the session vs the last half of the session). Therefore, our results only show the overall change in information flow in different phases of motor learning. Whether these changes can be used to explain behavioral variations across individual trials needs additional investigation.

With the above provisos in mind, we have provided evidence for the involvement of the STN and its connections with the sensorimotor cortex in the early phase of visuomotor adaptation and, more generally, for the role of STN and these connections in the monitoring and evaluation of movement errors and in subsequent motor adjustment. Once a movement is finished, there is a brief increase in activity in the beta band that is coherent between the STN and sensorimotor cortex. The flow of information between these sites changes during adaptation, with the drive of 
the STN to sensorimotor cortical areas being increased when large movement errors are made that are contextually salient insofar as they provide information that can be used to optimize subsequent movements. This STN-to-sensorimotor cortex drive may help modulate local cortical processes that would otherwise act to maintain the parameters of the motor program that delivered the last movement (Tan et al., 2014).

\section{References}

Baccalá LA, Sameshima K (2001) Partial directed coherence: a new concept in neural structure determination. Biol Cybern 84:463-474. CrossRef Medline

Bayer HM, Glimcher PW (2005) Midbrain dopamine neurons encode a quantitative reward prediction error signal. Neuron 47:129-141. CrossRef Medline

Brittain JS, Brown P (2014) Oscillations and the basal ganglia: motor control and beyond. Neuroimage 85:637-647. CrossRef Medline

Brown P (2007) Abnormal oscillatory synchronisation in the motor system leads to impaired movement. Curr Opin Neurobiol 17:656-664. CrossRef Medline

Brown P, Marsden J, Defebvre L, Cassim F, Mazzone P, Oliviero A, Grazia Altibrandi MG, Di Lazzaro V, Limousin-Dowsey P, Fraix V, Odin P, Pollak P (2001) Intermuscular coherence in Parkinson's disease: relation to bradykinesia. Neuroreport 12:2577-2581. CrossRef Medline

Cassidy M, Mazzone P, Oliviero A, Insola A, Tonali P, Di Lazzaro V, Brown P (2002) Movement-related changes in synchronisation in the human basal ganglia. Brain 125:1235-1246. CrossRef Medline

Cavanagh JF, Sanguinetti JL, Allen JJB, Sherman SJ, Frank MJ (2014) The subthalamic nucleus contributes to post-error slowing. J Cogn Neurosci 26:2637-2644. CrossRef Medline

Curran-Everett D (2000) Multiple comparisons: philosophies and illustrations. Am J Physiol Regul Integr Comp Physiol 279:R1-R8. Medline

Devos D, Labyt E, Derambure P, Bourriez JL, Cassim F, Reyns N, Blond S, Guieu JD, Destée A, Defebvre L (2004) Subthalamic nucleus stimulation modulates motor cortex oscillatory activity in Parkinson's disease. Brain 127:408-419. CrossRef Medline

Ding M, Bressler SL, Yang W, Liang H (2000) Short-window spectral analysis of cortical event-related potentials by adaptive multivariate autoregressive modeling: data preprocessing, model validation, and variability assessment. Biol Cybern 83:35-45. CrossRef Medline

Doyon J, Benali H (2005) Reorganization and plasticity in the adult brain during learning of motor skills. Curr Opin Neurobiol 15:161-167. CrossRef Medline

Doyon J, Bellec P, Amsel R, Penhune V, Monchi O, Carrier J, Lehéricy S, Benali H (2009) Contributions of the basal ganglia and functionally related brain structures to motor learning. Behav Brain Res 199:61-75. CrossRef Medline

Engel AK, Fries P (2010) Beta-band oscillations_signalling the status quo? Curr Opin Neurobiol 20:156-165. CrossRef Medline

Foltynie T, Hariz MI (2010) Surgical management of Parkinson's disease. Expert Rev Neurother 10:903-914. CrossRef Medline

Frank MJ, Seeberger LC, O’Reilly RC (2004) By carrot or by stick: cognitive reinforcement learning in Parkinsonism. Science 306:1940-1943. CrossRef Medline

Graybiel AM, Aosaki T, Flaherty AW, Kimura M (1994) The basal ganglia and adaptive motor control. Science 265:1826-1831. CrossRef Medline

Haufe S, Nikulin VV, Müller KR, Nolte G (2013) A critical assessment of connectivity measures for EEG data: a simulation study. Neuroimage 64:120-133. CrossRef Medline

Herrojo Ruiz M, Huebl J, Schönecker T, Kupsch A, Yarrow K, Krauss JK, Schneider GH, Kühn AA (2014) Involvement of human internal globus pallidus in the early modulation of cortical error-related activity. Cereb Cortex 24:1502-1517. CrossRef Medline

Hirschmann J, Özkurt TE, Butz M, Homburger M, Elben S, Hartmann CJ, Vesper J, Wojtecki L, Schnitzler A (2013) Differential modulation of STN-cortical and cortico-muscular coherence by movement and levodopa in Parkinson's disease. Neuroimage 68:203-213. CrossRef Medline

Houk JC, Adams JL, Barto AG (1995) A model of how the basal ganglia generate and use neural signals that predict reinforcement. In: Models of information processing in the basal ganglia (Houk JC, Davis JL, Beiser
DG, eds), pp 249-270. Cambridge, MA: Massachusetts Institute of Technology.

Howe MW, Atallah HE, McCool A, Gibson DJ, Graybiel AM (2011) Habit learning is associated with major shifts in frequencies of oscillatory activity and synchronized spike firing in striatum. Proc Natl Acad Sci U S A 108:16801-16806. CrossRef Medline

Kamiński MJ, Blinowska KJ (1991) A new method of the description of the information flow in the brain structures. Biol Cybern 65:203-210. CrossRef Medline

Körding KP, Wolpert DM (2004) Bayesian integration in sensorimotor learning. Nature 427:244-247. CrossRef Medline

Korenberg AT, Ghahramani Z (2002) A Bayesian view of motor adaptation. Curr Psychol Cogn 21:537-564.

Krakauer JW, Ghilardi MF, Mentis M, Barnes A, Veytsman M, Eidelberg D, Ghez C (2004) Differential cortical and subcortical activations in learning rotations and gains for reaching: a PET study. J Neurophysiol 91:924933. Medline

Krebs HI, Brashers-Krug T, Rauch SL, Savage CR, Hogan N, Rubin RH, Fischman AJ, Alpert NM (1998) Robot-aided functional imaging: application to a motor learning study. Hum Brain Mapp 6:59-72. CrossRef Medline

Kühn AA, Kempf F, Brücke C, Gaynor Doyle L, Martinez-Torres I, Pogosyan A, Trottenberg T, Kupsch A, Schneider GH, Hariz MI, Vandenberghe W, Nuttin B, Brown P (2008) High-frequency stimulation of the subthalamic nucleus suppresses oscillatory beta activity in patients with Parkinson's disease in parallel with improvement in motor performance. J Neurosci 28:6165-6173. CrossRef Medline

Lachaux JP, Rodriguez E, Martinerie J, Varela FJ (1999) Measuring phase synchrony in brain signals. Hum Brain Mapp 8:194-208. CrossRef Medline

Lalo E, Thobois S, Sharott A, Polo G, Mertens P, Pogosyan A, Brown P (2008) Patterns of bidirectional communication between cortex and basal ganglia during movement in patients with Parkinson disease. J Neurosci 28 : 3008-3016. CrossRef Medline

Liljeholm M, O'Doherty JP (2012) Contributions of the striatum to learning, motivation, and performance: an associative account. Trends Cogn Sci 16:467-475. CrossRef Medline

Litvak V, Eusebio A, Jha A, Oostenveld R, Barnes G, Foltynie T, Limousin P, Zrinzo L, Hariz MI, Friston K, Brown P (2012) Movement-related changes in local and long-range synchronization in Parkinson's disease revealed by simultaneous magnetoencephalography and intracranial recordings. J Neurosci 32:10541-10553. CrossRef Medline

Luft CD, Takase E, Bhattacharya J (2014) Processing graded feedback: electrophysiological correlates of learning from small and large errors. J Cogn Neurosci 26:1180-1193. CrossRef Medline

Marsden J, Limousin-Dowsey P, Fraix V, Pollak P, Odin P, Brown P (2001) Intermuscular coherence in Parkinson's disease: effects of subthalamic nucleus stimulation. Neuroreport 12:1113-1117. CrossRef Medline

Miall RC, King D (2008) State estimation in the cerebellum. Cerebellum 7:572-576. CrossRef Medline

Nakahara H, Itoh H, Kawagoe R, Takikawa Y, Hikosaka O (2004) Dopamine neurons can represent context-dependent prediction error. Neuron 41:269-280. CrossRef Medline

Nakano H, Osumi M, Ueta K, Kodama T, Morioka S (2013) Changes in electroencephalographic activity during observation, preparation, and execution of a motor learning task. Int J Neurosci 123:866-875. CrossRef Medline

Nakhnikian A, Rebec GV, Grasse LM, Dwiel LL, Shimono M, Beggs JM (2014) Behavior modulates effective connectivity between cortex and striatum. PLoS One 9:e89443. CrossRef Medline

Pollok B, Latz D, Krause V, Butz M, Schnitzler A (2014) Changes of motorcortical oscillations associated with motor learning. Neuroscience 275: 47-53. CrossRef Medline

Reynolds JN, Hyland BI, Wickens JR (2001) A cellular mechanism of reward-related learning. Nature 413:67-70. CrossRef Medline

Salenius S, Avikainen S, Kaakkola S, Hari R, Brown P (2002) Defective cortical drive to muscle in Parkinson's disease and its improvement with levodopa. Brain 125:491-500. CrossRef Medline

Scheidt RA, Zimbelman JL, Salowitz NM, Suminski AJ, Mosier KM, Houk J, Simo L (2012) Remembering forward: neural correlates of memory and prediction in human motor adaptation. Neuroimage 59:582-600. CrossRef Medline 
Seidler RD, Noll DC, Chintalapati P (2006) Bilateral basal ganglia activation associated with sensorimotor adaptation. Exp Brain Res 175:544-555. CrossRef Medline

Seth AK (2010) A MATLAB toolbox for Granger causal connectivity analysis. J Neurosci Methods 186:262-273. CrossRef Medline

Shadmehr R, Krakauer JW (2008) A computational neuroanatomy for motor control. Exp Brain Res 185:359-381. CrossRef Medline

Silberstein P, Pogosyan A, Kühn A, Hotton G, Tisch S, Kupsch A, DowseyLimousin P, Hariz MI, Brown P (2005) Cortico-cortical coupling in Parkinson's Disease and its modulation by therapy. Brain 128:1277-1291. CrossRef Medline

Tan H, Jenkinson N, Brown P (2014) Dynamic neural correlates of motor error monitoring and adaptation during trial-to-trial learning. J Neurosci 34:5678-5688. CrossRef Medline

Tobler PN, Fiorillo CD, Schultz W (2005) Adaptive coding of reward value by dopamine neurons. Science 307:1642-1645. CrossRef Medline

Tseng YW, Diedrichsen J, Krakauer JW, Shadmehr R, Bastian AJ (2007)
Sensory prediction errors drive cerebellum-dependent adaptation of reaching. J Neurophysiol 98:54-62. CrossRef Medline

Turner RS, Desmurget M (2010) Basal ganglia contributions to motor control: a vigorous tutor. Curr Opin Neurobiol 20:704-716. CrossRef Medline

Williams D, Tijssen M, Van Bruggen G, Bosch A, Insola A, Di Lazzaro V, Mazzone P, Oliviero A, Quartarone A, Speelman H, Brown P (2002) Dopamine dependent changes in the functional connectivity between basal ganglia and cerebral cortex in the human. Brain 125:1558-1569. CrossRef Medline

Wolpert DM, Miall RC (1996) Forward models for physiological motor control. Neural Netw 9:1265-1279. CrossRef Medline

Zavala B, Brittain JS, Jenkinson N, Ashkan K, Foltynie T, Limousin P, Zrinzo L, Green AL, Aziz T, Zaghloul K, Brown P (2013) Subthalamic nucleus local field potential activity during the Eriksen flanker task reveals a novel role for theta phase during conflict monitoring. J Neurosci 33:14758 14766. CrossRef Medline 